\title{
Modelling of a Sustainable Refugee Camp Drainage System for Stormwater Management
}

\author{
Oluwatoyin Opeyemi Ajibade, Kiran Tota-Maharaj, Colin D. Hills and Cecilia MacLeod \\ A novel decentralised Sustainable Refugee Camp Drainage System (SRCDS) has been developed for the effective \\ management of stormwater in the Dadaab refugee camp, Kenya. The SRCDS uses the principle of Best Management \\ Practices (BMPs) for runoff generated from extreme rainfall events in order to minimise flooding of inhabited areas of the \\ camp. The performance of the drainage system was modelled by the Storm-water Management Model (SWMM) and Micro \\ Drainage Sustainable Drainage Systems (MDSuDS) software to obtain: (i) the total stormwater flow in a sub-catchment in \\ order to obtain total runoff volume and peak runoff rate and (ii) the required dimensions of the SRCDS to effectively drain \\ and store runoff for reuse. The results showed that the total volume of runoff generated over the sub-catchment area \\ reduces significantly as the volume of water drained by the SRCDS increases, and the peak runoff rate decreases as the size \\ of the SRCDS increases. The SRCDS was effective in dealing with the peak rate and total volume of runoff anticipated.
}

\section{Introduction}

Amongst the main challenges to the implementation of suitable surface water drainage systems in refugee and temporary human settlement camps are the lack of detailed data (rainfall, topography etc.), inventive design and pressure for rapid construction (1). To help solve this problem, the present study investigates the suitability of a Sustainable Refugee Camp Drainage System (SRCDS) for the management of stormwater across the Dadaab refugee camp in Kenya, Africa. The design of SRCDS involves a decentralised approach using Best Management Practices (BMPs) for stormwater drainage close to the sources of generation (2).

A decentralised drainage system design is more suitable because:

(i) SRCDSs can be precisely installed near sources of overland flow to prevent localised ponding and flooding of inhabited areas;

(ii) implementation can be completed in phases for each sub-catchment;

(iii) the drainage model is easy to install in newly occupied parts of a camp as the refugee population increases;

(iv) the need for a single catchment-based solution involving long end-to-end pipes or channels (discharging to a camp-wide outlet or a central waste water treatment system) is reduced or eliminated;

(v) the level of wastewater treatment required is simplified because the design is tailored to each subcatchment based on use such as residential, communal, a school or market area. 
Whilst the SRCDS functions in a similar way to other BMPs, the drainage outlets have under-drain pipes that convey drained and filtered water to the nearest tank in each sub-catchment for storage or reuse. Collecting and storing water for reuse is a more sustainable solution for the Dadaab camp, particularly during critical drought situations as experienced in 2003-2005, 2005-2006, 2009 and 20172018 (3-5).

The SRCDS stormwater management strategy (see Fig. 1) diminishes the need for complex and onerous soil infiltration testing required by conventional drainage and traditional designs as water is directed, drained and filtered directly to tanks to reduce infiltration into the ground of the sub-catchments.

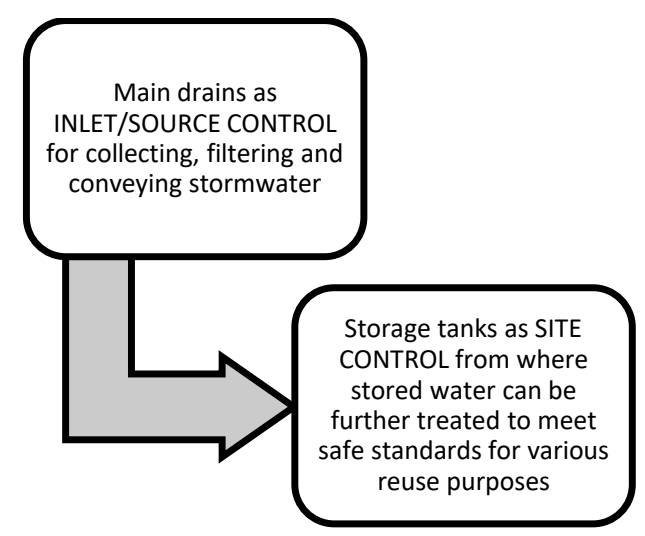

Figure 1-SRCDS storm-water management strategy

\section{Surface Water Drainage Systems in Refugee Camps}

Surface water drainage and wastewater management infrastructure are required to drain storm and wastewater to minimise the environmental and human health impacts caused especially during flooding events (6). A Gap Analysis in Emergency WASH Promotion, conducted by Bastable and Russell (7) for Humanitarian Innovation Fund (HIF), found poor drainage was one of the main environmental challenges faced by refugee camps. Similarly, WASH Exploration Reports on Surface Water Drainage compiled by Tota-Maharaj (8) for HIF, revealed that effective drainage systems are required for refugee camps to prevent flooding and localised ponding of water.
Alford-Daniel et al. (9) included the following requirements for setting up refugee camps:

- A technically appropriate drainage system must be provided, to ensure protection from standing wastewater and flooding.

- The drainage system must be regularly maintained by refugees and the Water, Sanitation and Hygiene (WASH) Committees.

- The slope of the camp site, the type of soil and the degree of infiltration must be taken into consideration when planning and installing drainage systems.

- Attention must be given to drainage systems with WASH infrastructure, such as toilets and water taps.

- Tools and materials must be available to refugees to protect their shelters and infrastructure from flooding and wastewater inundation.

Poor surface water management provides a breeding ground for disease vectors and decreased water quality in refugee camps (10). The solutions proposed included the need to (10):

- Inform and raise awareness about the importance of the appropriate management of surface water on-site,

- Support practitioners to better understand surface water management constraints and opportunities, and

- Enable practitioners to select and design/retrofit suitable drainage solutions for sites around the world (including the use of sustainable drainage systems).

To help overcome the identified problems of absence of suitable surface water drainage systems in refugee camps and limited time for designing the drainage systems, the application of pragmatic design approach was proposed by CIRIA (1) as feasible solution. 


\subsection{Design of surface water drainage systems for refugee camps}

The design of drainage systems for towns and cities is unlike that of refugee camps and temporary settlements as it requires innovative numerical modelling techniques for the optimisation of the design process. Numerical modelling has been used by academics and industry experts for designing surface water drainage systems for cities and towns with tools such as Micro-drainage and Storm Water Management Model (SWMM) (11-13). However, the numerical modelling techniques have not been applied to the more challenging environment of refugee camps (11-12).

Therefore, the objective of this research is to study the applicability of numerical modelling for designing surface water drainage systems for refugee camps, using the Dadaab camp in Kenya as the case study.

\subsection{Dadaab refugee camp, Garissa County, Kenya}

The Dadaab Refugee Camp is in Garissa County, Kenya and has a total of 211,701 registered refugees and asylum seekers in May 2019 (14). The three sections of the Dadaab camp; Ifo, Dagahaley and Hagadera were established between 1991 and 1992 and are operated by the United Nations High Commissioner for Refugees (UNHCR) (14-15).

The majority of the refugees are displaced persons from neighbouring countries such as Somalia, Ethiopia and Sudan (16) and they live in shelters provided by the UNHCR. Salmio (16) identified key environmental events such as the 2011 Eastern Africa drought as one of the major factors forcing refugees from their homes. Figure 2 illustrates the location of Dadaab refugee camp, whereas Figure 3 shows the shelters employed in the camp where surface water drainage is absent.

\subsubsection{Weather and soil data for the Dadaab refugee camp}

In designing surface water drainage systems, rainfall records and other weather information (frequency of rainfall and sunshine hours) are required as part of input data for modelling the rainfall/runoff transformation processes in the catchment. Likewise, soil characteristics in a catchment is also vital input data required for modelling the proportion of rainfall that is lost through infiltration (an important hydraulic process of the rainfall-runoff transformation process).
The historical weather data set for the Dadaab refugee camp was obtained from the Kenya Meteorological Department and World

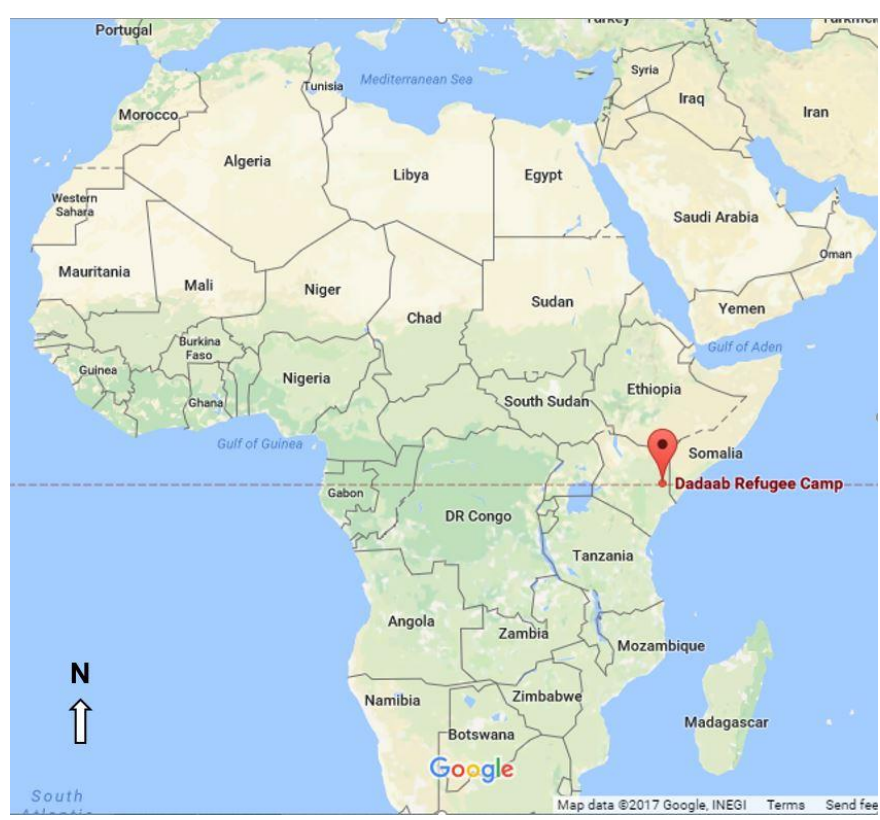

Figure 2 - Location of Dadaab refugee camp, Kenya, Eastern Africa (19)

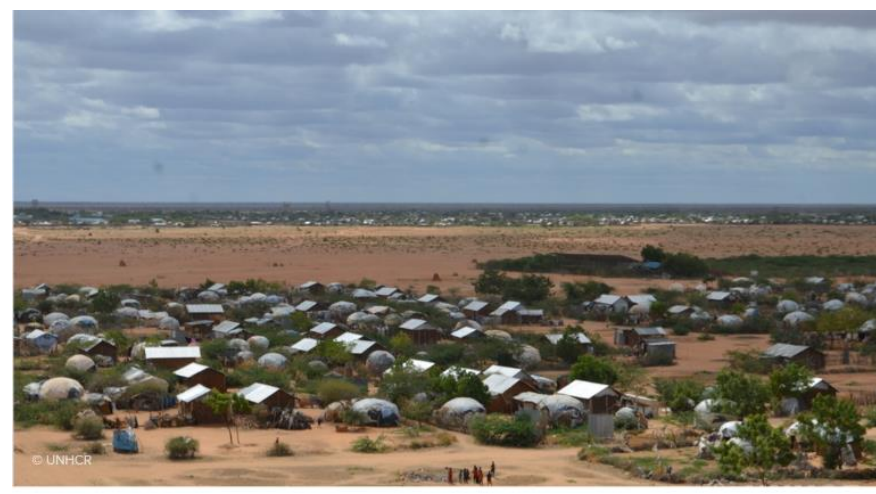

Figure 3-A view of the Dadaab refugee camp (Note that a surface water drainage is absent for the types of shelter available; 14)

Weather and Climate database (17-18).

The weather dataset (World Weather and Climate database for 2010 to 2019) (Table 1) included monthly rainfall data, raining days per month, maximum and minimum temperature, sunshine hours and relative humidity. The Kenya Meteorological Department supplied total daily values of rainfall and minimum and maximum temperature recorded at the Garissa meteorological station.

The soil information for the Dadaab camp was obtained from Cambrézy (20) and GoK (21). The soil of the Ifo section of the Dadaab refugee camp is a grey to grey-brown clay which may be calcareous or moderately to strongly saline, and/or gypsic. 
Garrisa in Kenya (2010-2019)

\begin{tabular}{lllllll}
\hline Month & $\begin{array}{l}\text { Total } \\
\text { rainfall } \\
(\mathbf{m m})\end{array}$ & $\begin{array}{l}\text { Rainy } \\
\text { Days } \\
\text { per } \\
\text { month }\end{array}$ & $\begin{array}{l}\text { Max. } \\
\text { Temp. } \\
\left({ }^{\circ} \mathbf{C}\right)\end{array}$ & $\begin{array}{l}\text { Min. } \\
\text { Temp. } \\
\left({ }^{\circ} \mathbf{C}\right)\end{array}$ & $\begin{array}{l}\text { Sunshine } \\
\text { Hours }\end{array}$ & $\begin{array}{l}\text { Relative } \\
\text { Humidity } \\
(\%)\end{array}$ \\
\hline Jan. & 10.0 & 3.0 & 36.0 & 22.0 & 250.0 & 59.0 \\
Feb. & 7.0 & 1.0 & 37.0 & 23.0 & 240.0 & 60.0 \\
Mar. & 28.0 & 4.0 & 38.0 & 24.0 & 265.0 & 60.0 \\
Apr. & 60.0 & 6.0 & 37.0 & 24.0 & 275.0 & 61.0 \\
May & 18.0 & 3.0 & 35.0 & 23.0 & 280.0 & 60.0 \\
Jun. & 6.0 & 1.0 & 34.0 & 21.0 & 252.0 & 60.0 \\
Jul. & 2.0 & 1.0 & 33.0 & 21.0 & 252.0 & 59.0 \\
Aug. & 7.0 & 1.0 & 33.0 & 21.0 & 255.0 & 60.0 \\
Sep & 7.0 & 3.0 & 35.0 & 21.0 & 275.0 & 58.0 \\
Oct. & 21.0 & 4.0 & 36.0 & 23.5 & 280.0 & 58.0 \\
Nov. & 78.0 & 7.0 & 36.0 & 23.5 & 250.0 & 62.0 \\
Dec. & 66.0 & 7.0 & 35.0 & 23.5 & 248.0 & 70.0 \\
\hline
\end{tabular}

Source: Kenya Meteorological Department (17) and World Weather and Climate database (18)

The soil promotes ponding and surface water flow on account of its low permeability (20-21). Unlike where river overflow is a main cause of surface water flooding, there is no nearby water course or natural hydro-system (3). Localised ponding of water and persistent flooding across the Ifo and Dagahaley sections of the camp are compounded by soil hardening during drought and by the activities of the refugees which include cutting down of trees for firewood and clearing vegetation for communal space $(5,20,22)$. Recent examples of flooding that occurred in 2015, 2017 and $2018(3,22)$ underpinned the need for an effective surface water drainage management strategy.

\section{Methods}

The process of modelling SRCDS was completed for a sub-catchment in five main steps summarised in Fig. 4.

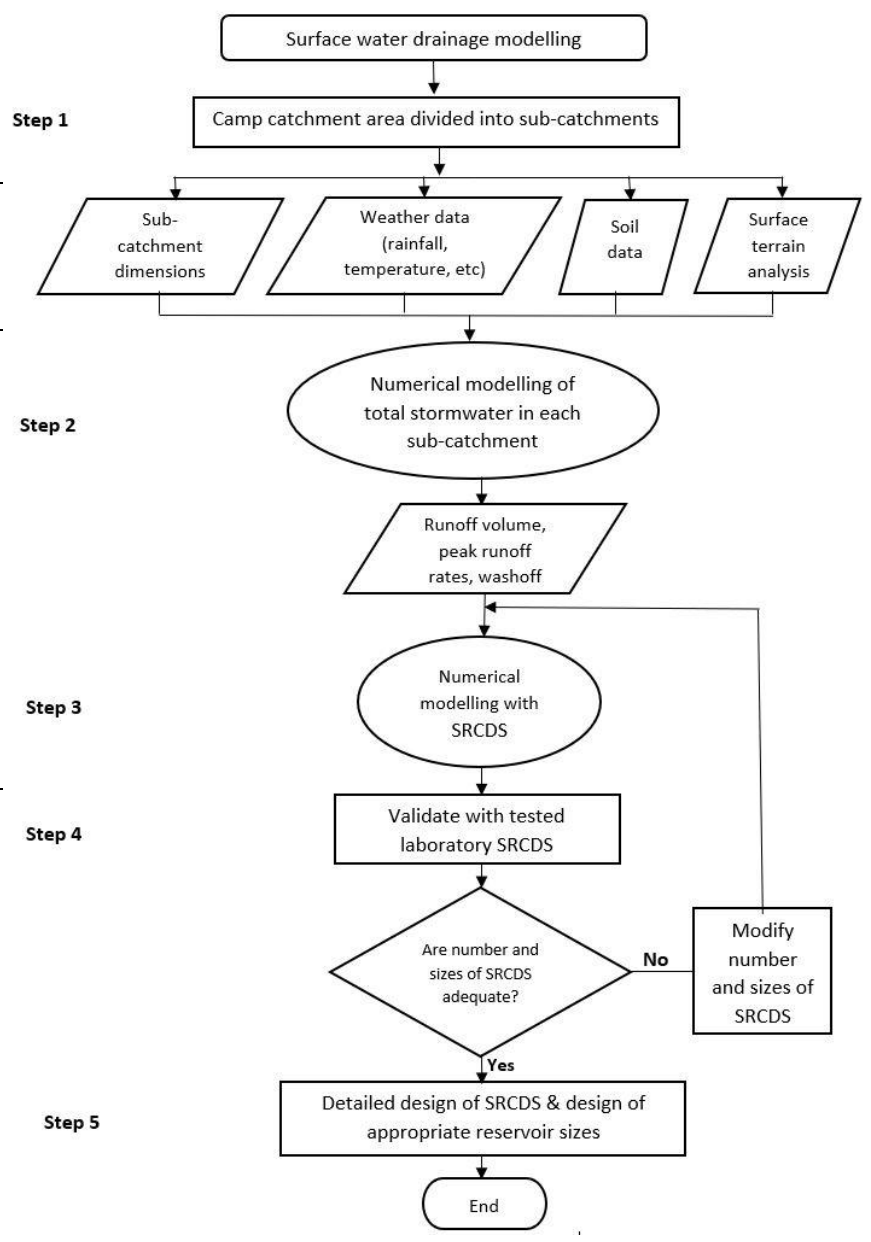

Figure 4 - Flow diagram of the SRCDS sub-catchment model

\subsection{Sub-division of catchment area (Step 1)}

The first step of the modelling process involved dividing one of the catchment areas of the camp (Fig. 5a) into sub-catchments and generating the ground level elevation differences.

The sub-catchments identified for the Ifo section (one of the frequently flooded catchment areas of the camp) was based on the contours of the catchment and was obtained using Google Earth Pro, CAD-Earth tool in AutoCAD and AutoCAD Map 3D software packages (Fig. 5b). Sub-catchment area (SC1) was gently undulating, with the difference in elevation across the site being $3 \mathrm{~m}$. 


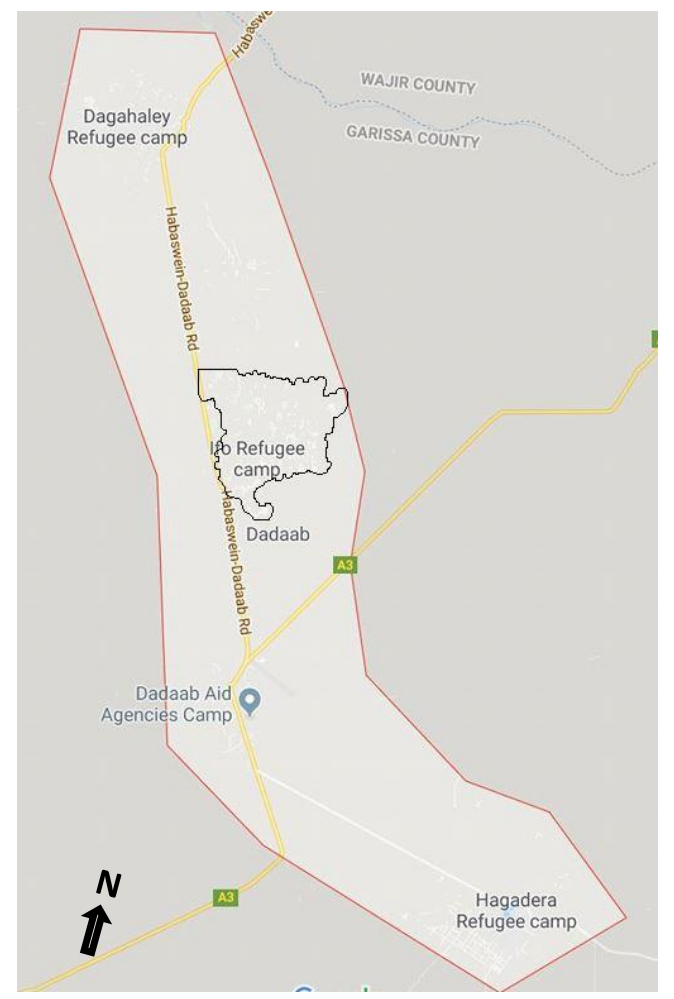

Figure 5a - The main catchment areas of the Dadaab refugee camp: Dagahaley, Ifo and Hagadera

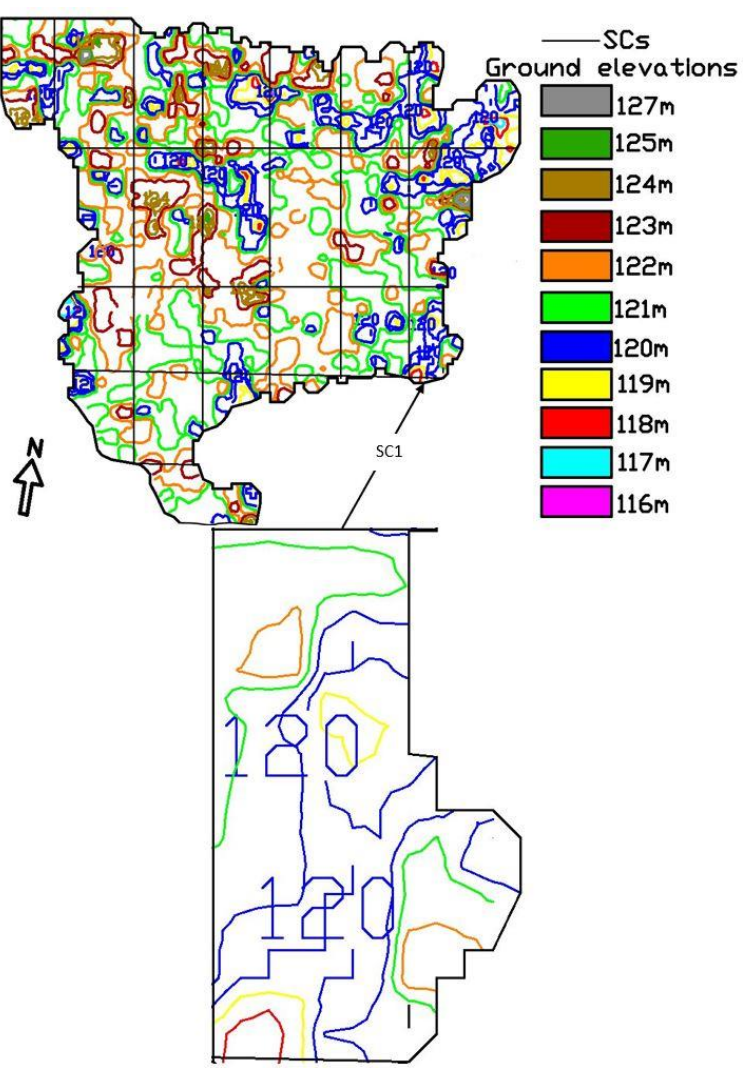

Figure $5 \mathrm{~b}$ - Ifo catchment of Dadaab camp divided into sub-catchments (SCs) based on ground elevation characteristics
The contour map of SC1 (Fig. 5b) shows ground elevations were ranging between $122 \mathrm{~m}$ and $118 \mathrm{~m}$ and indicated the areas where surface water will naturally pond.

\subsubsection{Sub-catchment area measurement}

The perimeter and area of SC1 were determined using Google Earth Pro and AutoCAD software packages (Fig. 6).

A summary of ground elevations along the perimeter of SC1 and its area are presented in Table 2.

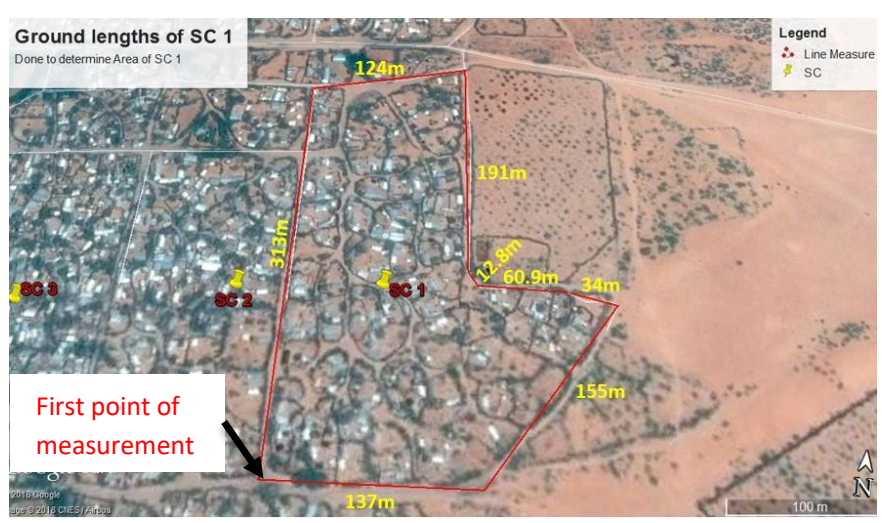

Figure 6 - Dimensions of SC1 $\left(\right.$ Total area $\left.=47624 \mathrm{~m}^{2}\right)$

Table 2: Geometry of sub-catchment 1 (SC 1) from Fig. 6 clockwise from the western edge and ground elevations shown in Fig. $5 \mathrm{~b}$

\begin{tabular}{|c|c|c|c|}
\hline Measurement & Length (m) & $\begin{array}{l}\text { Elevations } \\
\text { (m) }\end{array}$ & $\begin{array}{l}\text { Calculated } \\
\text { totals SC1 }\end{array}$ \\
\hline 1 & 313 & $118,120,122$ & \multirow{5}{*}{$\begin{array}{l}\text { Perimeter of } \\
\text { SC1 } \\
=1027.7 \mathrm{~m}\end{array}$} \\
\hline 2 & 124 & $119,120,122$ & \\
\hline 3 & 191 & $119,120,122$ & \\
\hline 4 & 12.8 & $121,121,121$ & \\
\hline 5 & 60.9 & $121,121,121$ & \\
\hline 6 & 34 & $121,121,121$ & \multirow{3}{*}{$\begin{array}{l}\text { Area of SC1 } \\
=47624 \mathrm{~m}^{2}\end{array}$} \\
\hline 7 & 155 & $120,121,122$ & \\
\hline 8 & 137 & $119,120,122$ & \\
\hline
\end{tabular}

\subsubsection{Simulation of design storms from historical weather datasets}

The annual maximum daily rainfall values were analysed for rainfall frequency to obtain the probability of occurrence of extreme events and corresponding return periods. The annual maximum values were ranked in decreasing order of magnitude (Table 3a). 
Table 3a: Rainfall frequency analysis

\begin{tabular}{cccc}
\hline $\begin{array}{c}\text { Annual } \\
\text { maximum daily } \\
\text { rainfall depths, } \\
\mathbf{R}(\mathbf{m m})\end{array}$ & $\begin{array}{c}\text { Ranked annual } \\
\text { maximum daily } \\
\text { rainfall, } \mathbf{R}_{\text {max }}\end{array}$ & Rank & $\begin{array}{c}\text { Deviation, } \mathbf{d} \\
|\mathbf{x}-\overline{\mathbf{x}}|^{\mathbf{2}}\end{array}$ \\
\hline $\mathbf{1 1 . 2}$ & 47 & 1 & 775.1 \\
\hline $\mathbf{1 1 . 1}$ & 14.3 & 2 & 23.6 \\
\hline $\mathbf{1 4 . 3}$ & 12.2 & 3 & 48.4 \\
\hline $\mathbf{1 2 . 2}$ & 11.2 & 4 & 63.36 \\
\hline $\mathbf{4 7}$ & 11.1 & 5 & 64.96 \\
\hline & $\sum \mathrm{R}_{\max }=95.8$ & & $\sum \mathrm{d}=975.4$ \\
\hline
\end{tabular}

The mean $(\overline{\mathrm{x}})$ and standard deviation (s) of the annual maximum daily rainfall $\left(R_{\max }\right)$ were obtained as $\bar{x}=19.16 \mathrm{~mm}$ and , $\mathrm{s}=13.97 \mathrm{~mm}$ respectively. Equations 1 to 3 were used to fit the analysed dataset to a Gumbel Fisher-Tippett Type 1 Extreme Distribution statistical probability plot in order to determine the probabilities of exceedance, $p$ of the annual maximum daily rainfall events, $R_{\max }$ for different return periods (see Fig. 7) (23):

$\mathrm{R}_{\max }=\mathrm{u}+\alpha \mathrm{y}$

Where,

$\mathrm{u}=$ mode (the location statistic)

$\alpha=$ slope (the scale statistic)

$y=$ reduced variate

For $45 \%$ probabilistic risk,

$$
\begin{aligned}
& \mathrm{u}=\overline{\mathrm{x}}-0.45(\mathrm{~s}) \\
& \alpha=0.78(\mathrm{~s})
\end{aligned}
$$

Using equations (2a) and (2b), $\mathrm{u}=12.9 \mathrm{~mm}$ and $\alpha=10.9 \mathrm{~mm}$ respectively.

To obtain a linear plot of the Gumbel distribution, the reduced variate values for corresponding probabilities of exceedance $(p)$ presented in Table $2 \mathrm{~b}$ were obtained using equation $2 \mathrm{c}$ :

$y=-\ln (-\ln (1-p))$
Similarly, the return periods ( $\mathrm{T}$ ) for probabilities of exceedance of the extreme maximum annual rainfall events were obtained using equation 3 :

$\mathrm{T}=\frac{1}{\mathrm{p}}$

The derived datasets for plotting the linear graph of the Gumbel distribution shown in Fig. 7 are presented in Table 3b.

Table 3b: Probabilities of exceedance of annual maximum rainfall events and the corresponding return periods

\begin{tabular}{cccc}
\hline $\begin{array}{c}\text { Probability of } \\
\text { exceedance, } \mathbf{p}\end{array}$ & $\begin{array}{c}\text { Return period, } \\
\mathbf{T} \text { (years) }\end{array}$ & $\begin{array}{c}\text { Reduced } \\
\text { variate, } \mathbf{y}\end{array}$ & $\mathbf{R}_{\max }(\mathbf{m m})$ \\
\hline 0.9 & 1.11 & -0.83 & 3.79 \\
\hline 0.7 & 1.43 & -0.19 & 10.85 \\
\hline 0.5 & 2 & 0.37 & 16.87 \\
\hline 0.2 & 5 & 1.50 & 29.22 \\
\hline 0.1 & 10 & 2.25 & 37.40 \\
\hline 0.05 & 20 & 2.97 & 45.23 \\
\hline 0.04 & 25 & 3.20 & 47.72 \\
\hline 0.02 & 50 & 3.90 & 55.38 \\
\hline 0.01 & 100 & 4.60 & 62.99 \\
\hline 0.005 & 200 & 5.30 & 70.57 \\
\hline 0.002 & 500 & 6.21 & 80.57 \\
\hline & & &
\end{tabular}

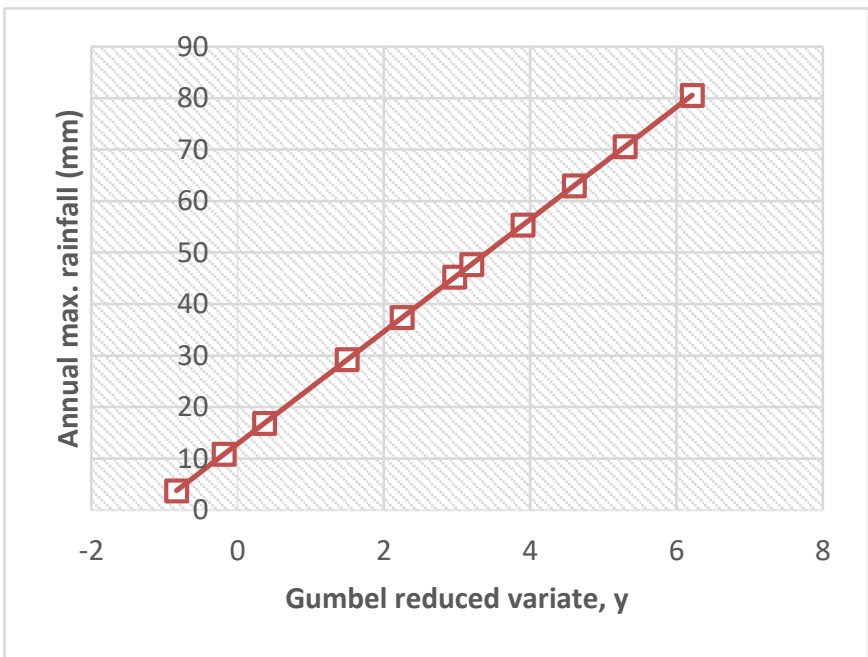

Figure 7 - Gumbel prediction for the reoccurrence of annual maximum rainfall (Probabilities shown are for return periods, $\mathrm{T}=1$ to 500 years)

From the linear Gumbel distribution graph (Fig. 7) and Table 3b, probabilities of extreme rainfall events occurring were determined. This shows that the $47.7 \mathrm{~mm}$ annual maximum annual rainfall depth will be equalled or exceeded in 25 years with a $4 \%$ probability of occurrence; while the annual maximum rainfall value of $17 \mathrm{~mm}$ will 
be equalled or exceeded in 2 years with a $50 \%$ chance of occurring The $29 \mathrm{~mm}$ annual maximum daily rainfall with $20 \%$ probability of occurring every five years was chosen from Fig. 7 and Table $3 \mathrm{~b}$ as the design storm for SC1. This 'design storm' was used to determine the cost of implementing the drainage system, as the main cost-factor is the design storm flowrate which is related to return period.

From the annual maximum daily rainfall depths obtained from Fig. 7, intensity, duration and frequency (IDF) curves for the return periods, $\mathrm{T}=2,5$ and 25 years, were derived for the Dadaab camp using equation 4. The derived IDF curves are given in Fig.8.

$i=\frac{R_{\max }}{D} \times 60$

Where,

$$
\begin{gathered}
\mathrm{i}=\text { Rainfall intensity }(\mathrm{mm} / \mathrm{hr}) \\
\mathrm{R}_{\max }=\text { Annual maximum daily rainfall }(\mathrm{mm}) \\
\mathrm{D}=\text { Duration of rainfall }(\mathrm{min})
\end{gathered}
$$

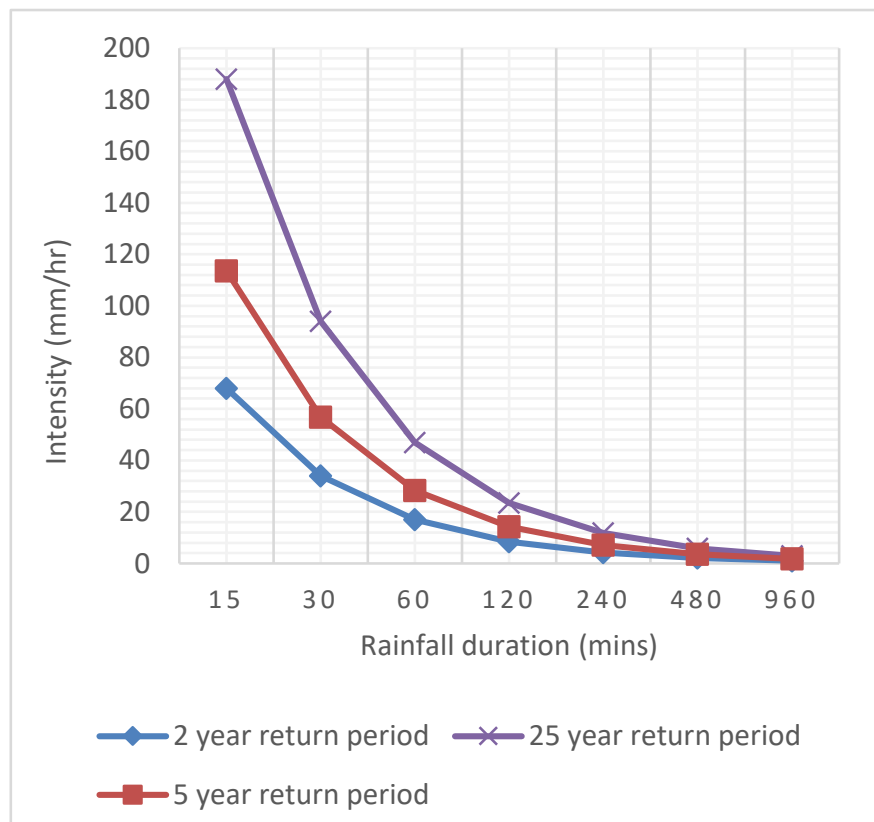

Figure 8 - Rainfall intensity, duration and frequency (IDF) curves for return periods $\mathrm{T}=$ 2,5 and 25 years

\subsection{Modelling sub-catchment total storm-water flow (Step} 2)

The outcomes of step 1 were input into step 2; the outputs of which were the total runoff volume generated over SC1 area and peak runoff rate without the drainage system (see Fig. 11). The modelling process undertaken using SWMM and MDSuDS software includes the calculation of the time of concentration using the Kinematic Wave method, infiltration rates using Modified Horton's equation and peak runoff rates and runoff volume using Unit Hydrograph method.

\subsubsection{Time of concentration $\left(t_{c}\right)$}

In order to calculate the velocity of stormwater runoff over SC1, the time of concentration $\left(t_{c}\right)$ was calculated using the Kinematic Wave Method (24-25). This method is more applicable as it gives more consistent results than Kirpich, Izzard, Kerby and NRCS methods of calculating time of concentration (24-26). The governing equation for the Kinematic Wave Method is given as equation 5 (26-27):

$\mathrm{t}_{\mathrm{c}}=\frac{6.99(\mathrm{~nL})^{0.6}}{\mathrm{i}^{0.4} \mathrm{~S}_{0}{ }^{0.3}}$

Where,

$$
\begin{aligned}
& \mathrm{n}=\text { Manning's roughness coefficient for overland flow } \\
& \mathrm{i}=\text { Rainfall intensity }(\mathrm{mm} / \mathrm{hr}) \\
& \mathrm{L}=\text { Flow path length }(\mathrm{m}) \\
& \mathrm{S}_{0}=\text { Ground slope } \\
& \mathrm{t}_{\mathrm{c}}=\text { Time of concentration }(\mathrm{min})
\end{aligned}
$$

The values of $S_{0}$ and $L$ were obtained from the scaled topography map. Manning's roughness, $n$ of 0.030 for packed clay was used (Crowford and Linsley, 1966 as cited by Butler and Davies (6)). The actual rainfall intensity for a storm with a duration of $\mathrm{t}_{\mathrm{c}}$ was obtained by applying trial by error approach to all the rainfall intensities along the $\mathrm{T}=5$ year curve (see Fig. 8). The procedure for the trial by error approach is as follows:

1. An assumed trial rainfall intensity was selected from rainfall intensities along the $\mathrm{T}=5$ year curve

2. Overland flow travel time, $t_{c}$ was calculated using equation 5.

3. Actual rainfall intensity for a storm with duration of $t_{c}$ was calculated

4. The rainfall intensities were compared 
5. Steps 1 to 4 were repeated until the calculated rainfall intensity was equal to the assumed rainfall intensity.

\subsubsection{Modelling of infiltration rate over sub-catchment SC 1} The Horton, Modified Horton, Green-Ampt, Curve Number and Richard methods were considered for modelling the surface water infiltration rates in sub-catchment SC1. However, the Modified Horton's method was employed as it uses the cumulative infiltration volume in excess of the minimum infiltration rate as its state variable, rather than time along the Horton decay curve used in the original method (26-27). This method also gives a more accurate estimation of infiltration for low rainfall intensities, because it accounts for a decrease in infiltration capacity with time as the difference between the actual and minimum infiltration rates that are accumulated just below the ground surface (6). The governing equations for modelling infiltration rate over SC1 are presented as equations 6 to $11(6,26)$ :

$f_{t}=f_{\infty}+\left(f_{0}-f_{\infty}\right) e^{-k t}$

Where,

$\mathrm{f}_{\mathrm{t}}=$ infiltration rate into the soil at time $\mathrm{t}(\mathrm{mm} / \mathrm{hr})$

$\mathrm{f}_{0}=$ initial (or maximum) value of $\mathrm{f}_{\mathrm{t}}($ at $\mathrm{t}=0)(\mathrm{mm} / \mathrm{hr})$

$f_{\infty}=$ minimum value of $f_{t}$ after the soil has been saturated (at $t$

$$
=\infty)(\mathrm{mm} / \mathrm{hr})
$$

$\mathrm{t}=$ time from beginning of storm (sec)

$\mathrm{k}=$ infiltration capacity decay coefficient $\left(\mathrm{hr}^{-1}\right)$

The total volume of infiltration, $\mathrm{F}$, after time $\mathrm{t}$ was obtained using equation 7

$F(t)=\int_{0}^{t} f_{t} d t=f_{\infty} t+\frac{\left(f_{0}-f_{\infty}\right)}{k}\left(1-e^{-k t}\right)$

Solving for $\mathrm{e}^{-\mathrm{kt}}$ from equation 6 and substituting into equation 7 gives equation 8 , then solving for $f_{t}$ in equation 6 gives equation 9 :

$F=f_{\infty} t+\frac{\left(f_{0}-f_{t}\right)}{k}$

$f_{t}=f_{0}-k\left(F-f_{\infty} t\right)$

Because $\mathrm{F}-\mathrm{f}_{\infty} \mathrm{t} \equiv \int_{0}^{\mathrm{t}}\left(\mathrm{f}-\mathrm{f}_{\infty}\right) \mathrm{dt}$, equation 9 was approximated as equations 10 to 11 :

$\mathrm{f}_{\mathrm{t}}=\mathrm{f}_{0}-\mathrm{kF}_{\mathrm{e}}$

$\mathrm{f}_{\mathrm{t}}=\mathrm{f}_{0}-\mathrm{k}\left(\sum_{\mathrm{i}}\left(\mathrm{f}_{\mathrm{i}}-\mathrm{f}_{\infty}\right) \Delta \mathrm{t}_{\mathrm{i}}\right)$

$$
\begin{aligned}
& \mathrm{i}=\text { rainfall rate over } \mathrm{SC} 1 \text { area }(\mathrm{mm} / \mathrm{hr}) \\
& \mathrm{f}_{\mathrm{i}}=
\end{aligned}
$$

actual infiltration rate over a preceding time interval $\Delta \mathrm{t}_{\mathrm{i}}(\mathrm{mm} / \mathrm{hr})$, and

$f_{i}$ is the smaller of $f_{t}$ and $i$

\begin{tabular}{|c|c|c|c|}
\hline Property & Value & Unit & References \\
\hline $\mathbf{f}_{0}$ & 25.4 & $\mathrm{~mm} / \mathrm{hr}$ & $\begin{array}{l}\text { Recommended value for dry clay } \\
\text { soil with little or no vegetation, } \\
\text { such as SC1 after a drought (6). }\end{array}$ \\
\hline $\mathbf{f}_{\infty}$ & $1.27-0$ & $\mathrm{~mm} / \mathrm{hr}$ & $\begin{array}{l}\text { Recommended range of values by } \\
\text { NRCS for Hydrologic soil Group D } \\
\text { (poorly drained, clayey soils such as } \\
\text { SC1) (Musgrave, } 1955 \text { as cited by } \\
\text { (6)). }\end{array}$ \\
\hline $\mathbf{k}$ & 130 & $\mathrm{hr}^{-1}$ & $\begin{array}{l}\text { Value obtained for SC1 through the } \\
\text { iterative process from } \mathrm{k} \text { of } 120 \\
\mathrm{hr}^{-1} \text { recommended for sandy-clay } \\
\text { soil (6). }\end{array}$ \\
\hline Drying time & 6 & $\mathrm{hr}$ & $\begin{array}{l}\text { Value obtained for time taken for } \\
\text { SC1 soil to start drying after being } \\
\text { saturated }\end{array}$ \\
\hline
\end{tabular}

The values of infiltration data used for SC1 are provided in Table 4.

Table 4: Infiltration constants used for SC1

\subsubsection{Numerical modelling of runoff rate and volume over sub- catchment SC 1}

After the design storm hyetograph (plot of rainfall intensity against time) was defined, and losses were computed and subtracted from rainfall to compute runoff volume, the time distribution and magnitude of runoff was computed with a rainfall to runoff transform.

The methods of converting the excess precipitation into overland flow (surface runoff) include the Runoff Coefficient, Natural Resources Conservation Service (NRCS) and Unit Hydrograph methods (28). The generation of runoff over SC1 was done using the Unit Hydrograph method. This enabled accurate calculation of the rainfall to runoff transformation in the sub-catchment.

The governing equation for calculating the runoff rate using the nonlinear reservoir model approach was derived from the conservation of mass equation (6). In order to determine total runoff volume from the design storm, the volumetric flow rate of runoff over the rainfall duration was calculated using Manning's equation (25-27).

Where, 


\subsection{Modelling with SRCDS (Step 3)}

The outcomes of step 2 were inputs for step 3. The contour data presented in Fig. $5 \mathrm{~b}$ were used to identify existing natural channels/potential ponds of SC1 in order to correctly layout the SRCDS (Fig. 9a). The simulated SRCDSs for SC1 were three main drains (D1a, D1b and D2) (Figures 9a \& 9b) and two below ground level storage reservoirs (R1 and R2) (Fig. 9c). Runoff captured by D1a and D1b drained into R1 while that of D2 drained into R2. The objectives of designing the SRCDS D1a, D1b and D2 to have configurations illustrated in Fig. 9b were to: promote conveyance of stormwater at a controlled rate, enhance rate of drainage and act as a filter medium for removing pollutants. The reservoirs have two sections (Fig. 9c) to provide adequate storage of drained water, promote settling of sediments in the first section while clearer water flows to the second section and to provide adequate hydraulic head for pumping water from second section.

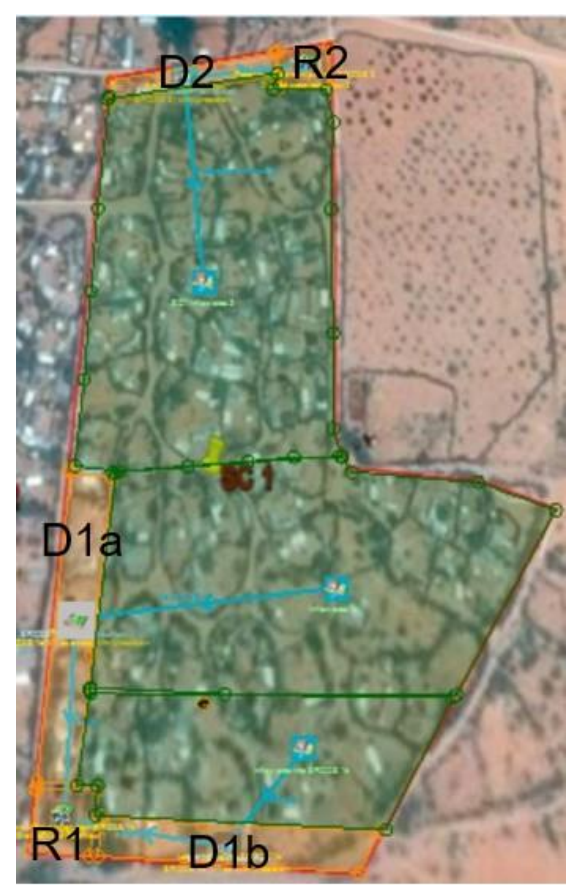

Figure 9a - Layout of the SRCDS D1a, D1b, D2 and reservoirs (R1 \& R2)

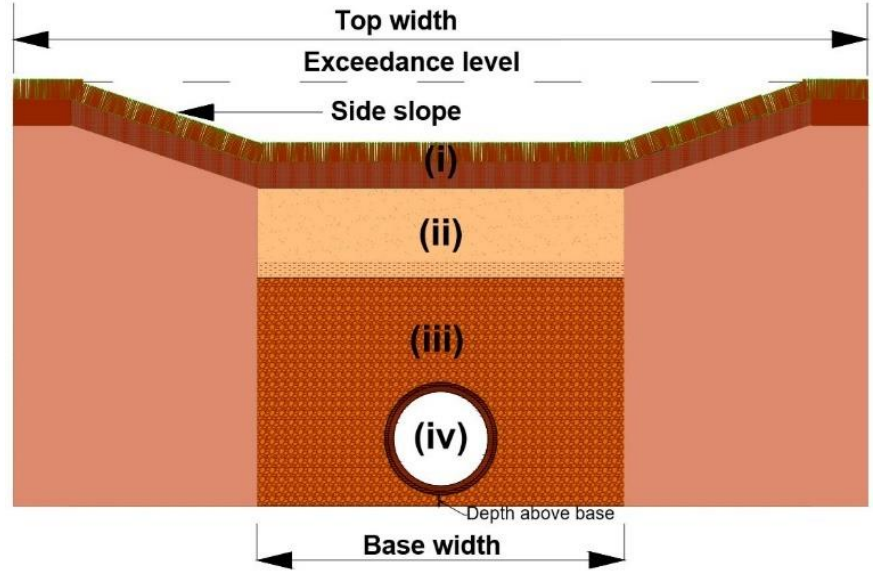

Figure $9 \mathrm{~b}$ - Cross section of SRCDS D1a, D1b and D2: (i) grass, (ii) filtration layer, (iii) storage layer, and (iv) underdrain perforated pipe: (Scale 1:120 @A4)

The specific functions of the SRCDSs components shown in Fig. 9b are:

(i) Bermuda grass (Cynodon dactylon), supported by 0.7 $\mathrm{m}$ deep engineered topsoil, to reduce silt, control velocity of stormwater flows and facilitate infiltration,

(ii) engineered filtration layer to enhance draining rate and reduce pollutants ( $0.14 \mathrm{~m}$ deep),

(iii) storage layer for drained water before discharge through underdrain pipe $(0.86-1.36 \mathrm{~m})$, and

(iv) underdrain perforated pipes connected to storage reservoirs (0.15 $\mathrm{m}$ diameter).

Bermuda grass was chosen because it is a perennial plant that grows well in extreme climatic conditions and all soil types (sand, clay, etc.) due to its extensive root system (29). In addition, the grass is native to Africa and could provide additional benefit to grazing animals of the refugees as feed (29). A $28.7 \%$ porosity filter media was simulated for the SRCDS 
to provide high draining rate and improvement of quality of drained water (30).

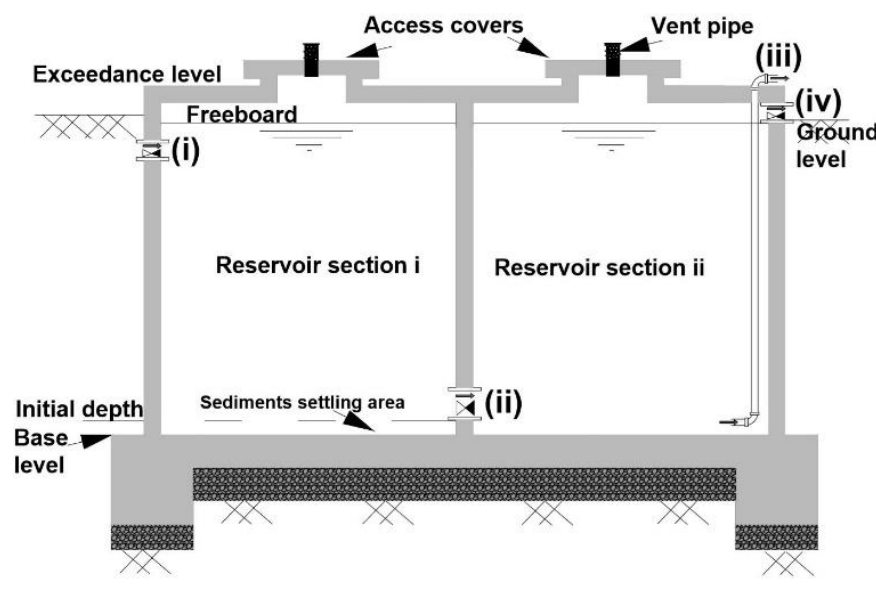

Figure 9c-Cross section of reservoirs R1 and R2: (i) inflow from SRCDS D1a, D1b \& D2 with a $0.25 \mathrm{~m}$ non-return valve, (ii) connection between sections of the reservoir with a $0.25 \mathrm{~m}$ non-return valve, (iii) $0.05 \mathrm{~m}$ outlet pipe connected to a pump, and (iv) Overflow outlet with a 0.25 m non-return valve: (Scale 1:100 @ A4)

Subsequently, the processes undertaken in step 2 were repeated with the SRCDSs.

The calculated time taken for runoff generated over SC1 to reach the SRCDSs from the farthest point of the sub-catchment (the time of concentration, $\mathrm{t}_{\mathrm{c}}$ ) are presented in Table 5 .

Table 5: Inflow areas contributing to SRCDS D1a, D1b and D2

\begin{tabular}{|c|c|c|c|c|c|}
\hline $\begin{array}{l}\text { Inflow } \\
\text { areas of } \\
\text { SC1 } \\
\text { SRCDS } \\
\text { drains }\end{array}$ & $L(m)$ & Area $\left(m^{2}\right)$ & $\begin{array}{l}\text { Manning's } \\
\text { roughness }\end{array}$ & $\begin{array}{l}\text { Actual i } \\
\text { (mm/hr) }\end{array}$ & $\begin{array}{l}t_{c} \\
(\min )\end{array}$ \\
\hline D1a & 200 & 14800 & 0.03 & 4.7 & 5.5 \\
\hline D1b & 40 & 7000 & 0.03 & 4.7 & 2.1 \\
\hline D2 & 148 & 14800 & 0.03 & 4.7 & 4.6 \\
\hline
\end{tabular}

\subsection{Validation of the SRCDS performance with laboratory tests (Step 4)}

The draining rates of the vertical flow components of SRCDS D1a, $\mathrm{D} 1 \mathrm{~b}$ and D2 were validated and calibrated with the laboratory-tested system shown in Fig. 10 (30). The experimental rig was built from a clear acrylic tube of $140 \mathrm{~mm}$ internal diameter and $150 \mathrm{~mm}$ external diameter, a three-dimensional (3D) base plate and water flow meter
(30). Rainfall was simulated as controlled inflow while outflow over a duration of one minute was obtained as draining rate (30). The same simulated SRCDS materials and filter media depth in step 3 were used for the laboratory scale system to enable comparison.

The validation of the draining rates was evaluated via the correlation between volume of water drained by the SRCDSs and laboratory scale system for a duration of one minute. If the sizes of the SRCDS were not adequate, step 3 was repeated iteratively until adequate sizes were achieved. Similarly, a regression analysis was undertaken to calibrate the SRCDS to obtain consistent draining rates for longer rainfall durations. The outcomes of this step are presented in Figures $12 \mathrm{a}-\mathrm{c}$.
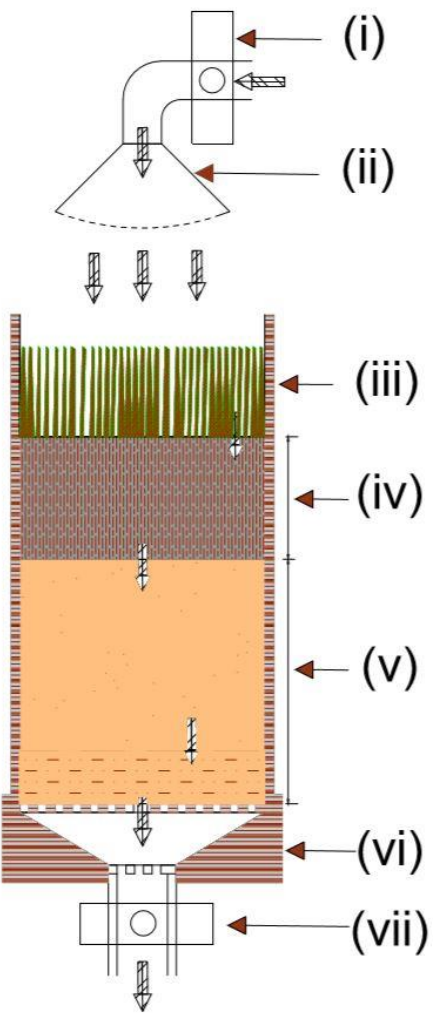

Figure 10 - Cross section of experimental rig for validating the draining rate of simulated filter media of the SRCDS: (i) inflow control valve, (ii) rainfall simulator, (iii) Bermuda grass, (iv) engineered garden soil (0.07 m deep), (v) filtration layer (0.14 m deep), (vi) base plate, and (vii) outflow control valve: (Scale 1:3 @ A4)

\subsection{Design of the SRCDS (Step 5)}

The outcomes of step 4 of the modelling process of the SRCDS were used to design the SRCDS sizes that are adequate for draining runoff generated for longer durations of the design storm. The design (see Fig. 9b) parameters of the SRCDS (Table 6) are for the systems that 
effectively drained the runoff generated from the design storm over 720 minutes.

Likewise, the design parameters of the reservoirs illustrated in Fig. $9 c$ are presented in Table 7.

Table 6: Design parameters of SRCDS D1a, D1b and D2

\begin{tabular}{lccc}
\hline SRCDS & D1a & D1b & D2 \\
\hline Exceedance level $(\mathbf{m})$ & 120 & 122 & 121 \\
\hline Freeboard $(\mathbf{m m})$ & 10 & 10 & 150 \\
\hline Length $(\mathbf{m})$ & 126.7 & 115.3 & 70.4 \\
\hline Slope (1x) & 10 & 10 & 10 \\
\hline Base width (m) & 4 & 4 & 8.9 \\
\hline Filtration layer base level & 118 & 119 & 118
\end{tabular}

(m)

\begin{tabular}{lccc}
\hline Side slope (1x) & 4 & 4 & 4 \\
\hline Top width (m) & 24 & 28 & 32.9 \\
\hline Porosity (\%) & 28.7 & 28.7 & 28.7 \\
\hline $\begin{array}{l}\text { Filtration layer filtration } \\
\text { rate (m/hr) }\end{array}$ & 0.463 & 0.463 & 0.463 \\
\hline $\begin{array}{l}\text { Filtration layer retention } \\
\text { coefficient }\end{array}$ & 0.45 & 0.45 & 0.45 \\
\hline $\begin{array}{l}\text { Depth of storage layer (m) } \\
\text { Storage layer retention }\end{array}$ & 1.5 & 1 & 1 \\
$\begin{array}{l}\text { coefficient } \\
\text { Underdrain depth above }\end{array}$ & 0.497 & 0.497 & 0.497 \\
base (m) & & 0.1 & 0.1 \\
\hline
\end{tabular}

Table 7: Design parameters of reservoirs R1 and R2

\begin{tabular}{lcc}
\hline Reservoirs & R1 & R2 \\
\hline Exceedance level $(\mathrm{m})$ & 118.5 & 119 \\
\hline Base level $(\mathrm{m})$ & 113.5 & 115 \\
\hline Freeboard $(\mathrm{mm})$ & 100 & 100 \\
\hline Initial depth $(\mathrm{m})$ & 0.1 & 0.1 \\
\hline $\begin{array}{l}\text { Dimension of each section } \\
\text { the reservoirs }\left(\mathbf{m}^{\mathbf{3}}\right)\end{array}$ & $12 \times 6 \times 5$ & $10 \times 6 \times 4$ \\
Length $\times$ width $\times$ depth & & \\
\hline
\end{tabular}

\section{Results and discussion}

\subsection{Storm-water runoff and infiltration volume generated} from design storms

The results given in Fig. 11 show that the runoff generated from the design storm decreased as the duration of storm increased. The peak runoff rate and runoff coefficient were $0.18 \mathrm{~m}^{3} / \mathrm{s}$ and 0.832 , respectively for a 3 -hr storm duration, $0.14 \mathrm{~m}^{3} / \mathrm{s}$ and 0.812 respectively for the $6 \mathrm{hrs}$ and $0.12 \mathrm{~m} / \mathrm{s}$ and 0.763 for the $12 \mathrm{hrs}$. Conversely, the proportion of runoff lost through infiltration increased as the duration of storm increased.

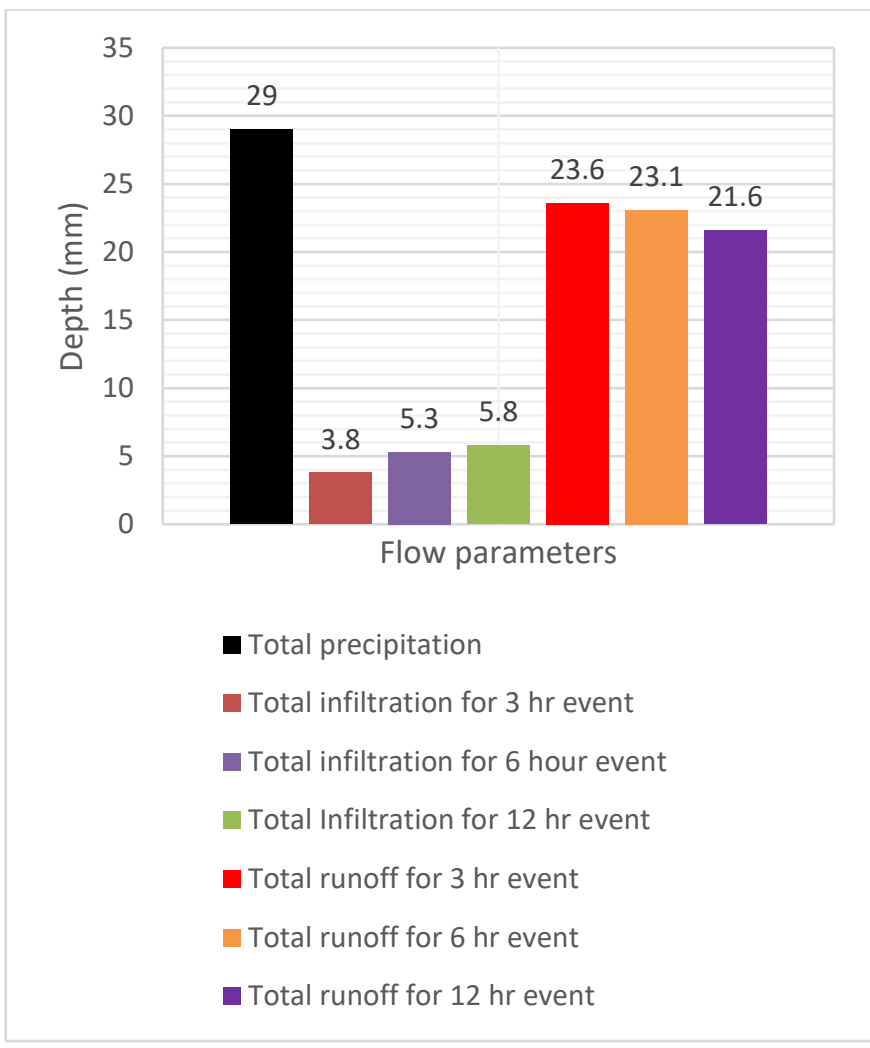

Figure 11 - Total infiltration and total runoff from the design storm

\subsection{Results of calibration \& validation of the SRCDS with laboratory tested system}

The comparison of draining rates of the SRCDS D1a, D1b and D2 with the laboratory tested system that are illustrated in Figures 12(a-c), confirms a high positive correlation $(r=0.978)$ between the drainage rates. The regression line equations for calibrating the D1a, D1b and D2 drainage rates with that of the laboratory tested system, are given in equations 12,13 and 14 , respectively: 


$$
\begin{aligned}
\mathrm{Q}_{\text {Lab }}^{\prime} & =0.0956 \mathrm{Q}_{\text {sim D1a }}-1.761 \times 10^{-5} \\
\mathrm{Q}_{\text {Lab }}^{\prime} & =0.1434 \mathrm{Q}_{\text {sim D1b }}-1.761 \times 10^{-5} \\
\mathrm{Q}_{\text {Lab }}^{\prime} & =0.0956 \mathrm{Q}_{\text {sim D2 }}-1.761 \times 10^{-5}
\end{aligned}
$$

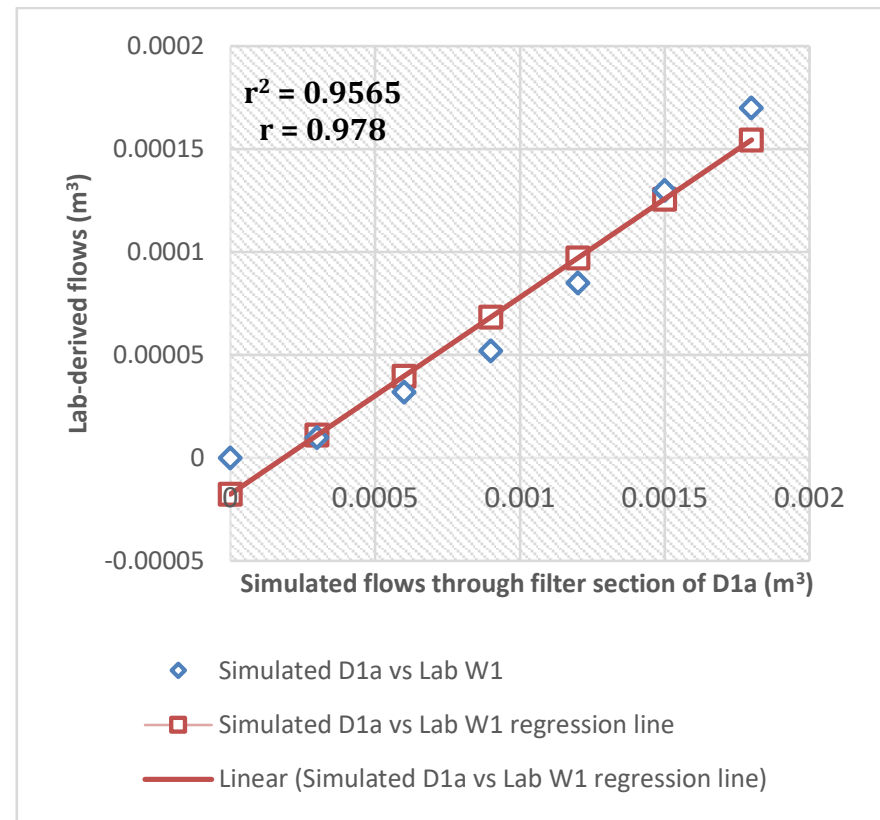

Figure 12a - Validation \& calibration of SRCDS D1a with lab-derived draining rates

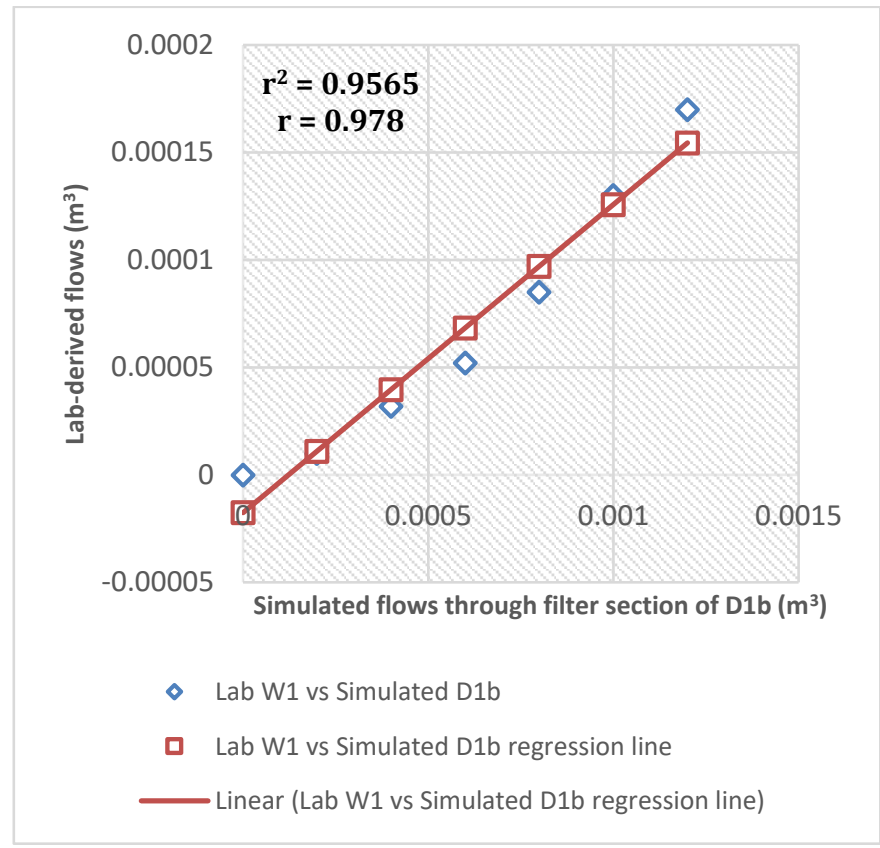

Figure $12 b$ - Validation \& calibration of SRCDS D1b with lab-derived draining rates

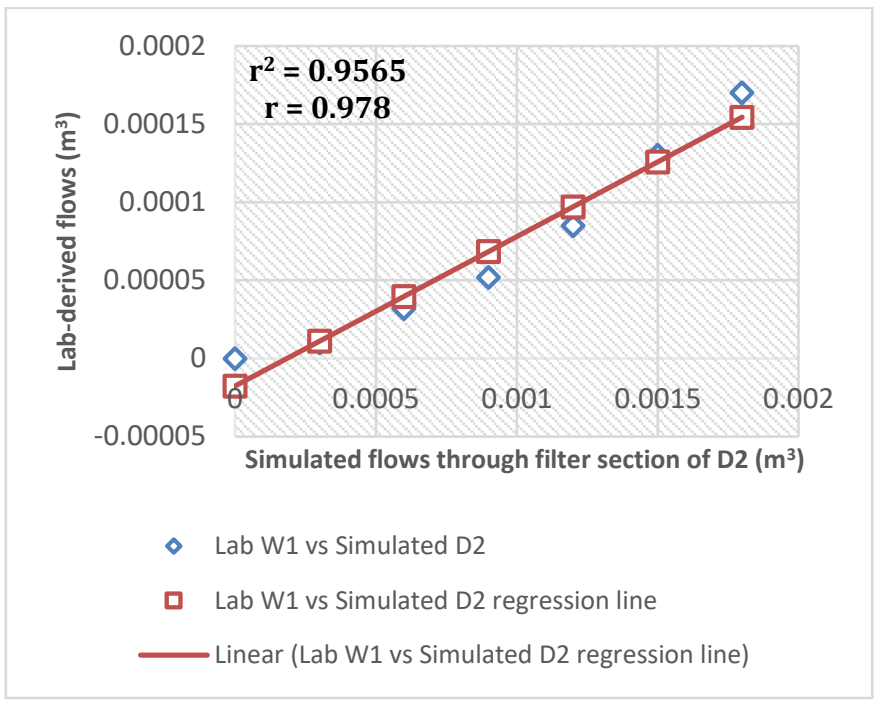

Figure $12 c$ - Validation \& calibration of SRCDS D2 with lab-derived draining rates

\subsection{Performance of the SRCDS}

The performance of the final drainage systems for managing runoff generated from the design storm are illustrated in Figures $13(a-c)$. From the results obtained for the three systems, the design storm, total inflow rates (proportion of runoff reaching each system per unit time) and total outflow rates (proportion of inflow drained by each system per unit time) become equal at 720 minutes. This outcome confirms that the runoff generated from the extreme storm event across SC1 was effectively managed by the SRCDS as soon as it was generated.

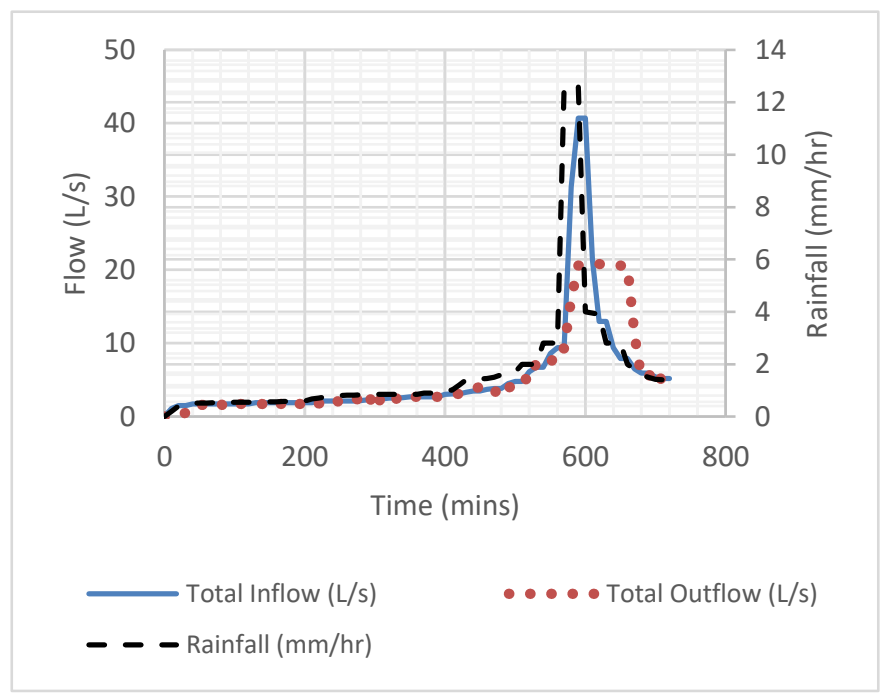

Figure 13a - Performance of SRCDS D1a 


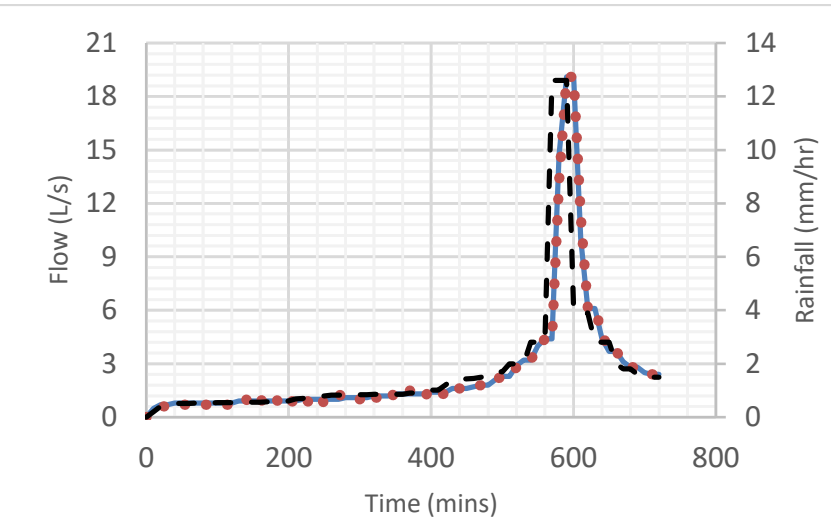

Total inflow (L/s)

- $\cdots$ Total Outflow $(\mathrm{L} / \mathrm{s})$

- - Rainfall ( $\mathrm{mm} / \mathrm{hr}$

Figure $13 b$ - Performance of SRCDS D1b

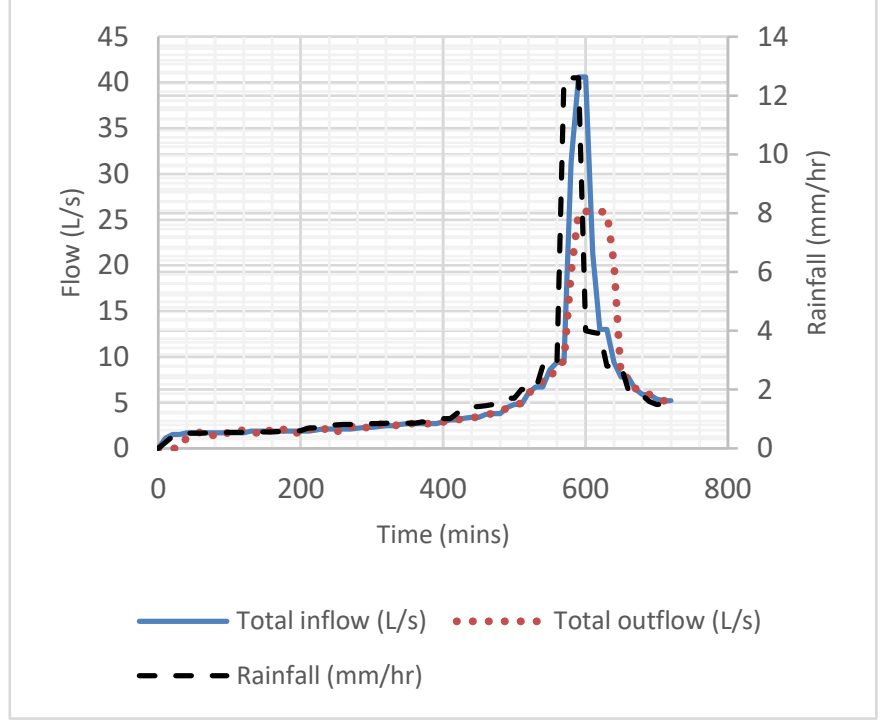

Figure $13 c-$ Performance of SRCDS D2
The summary performance evaluation for SRCDS presented in Table 8 , shows that the total volume of runoff (total lost volume) generated over the sub-catchment area reduces significantly as the volume of water drained (total discharge volume) by the SRCDS increases. The 'OK' status of the SRCDSs shows that the designs were appropriate. This significant volume of water collected by the systems (Table 8) indicates that the use of SRCDS for managing stormwater runoff could help meet the goal of providing refugees with water of adequate quantity and habitable environment (31-32).

\section{Conclusion}

The results obtained from employing the Sustainable Refugee Camp Drainage System for a sub-catchment of the Dadaab refugee camp has shown that numerical modelling techniques can be used to design effective drainage systems for these challenging sites. The SRCDS can reduce the runoff in sub-catchments via a decentralised drainage system, which is an ideal solution to the frequent flooding arising from storm events.

The simplified approach employed to model SRCDSs for a subcatchment can be applied more widely across a camp for designing drainage system for other sub-catchments of the camp. This provides a practical solution for managing stormwater. The water stored in the reservoir components of SRCDSs can provide a useful source for non-potable water for use during drought periods. However, further treatment of stored water would be necessary prior to use for domestic purposes

Table 8: Performance of SRCDSs (drains D1a, D1b, D2 and reservoirs R1 and R2) across the SC1 during the design storm

\begin{tabular}{|c|c|c|c|c|c|c|c|c|}
\hline SRCDS & $\begin{array}{l}\text { Max. } \\
\text { Level } \\
\text { (m) }\end{array}$ & $\begin{array}{l}\text { Max. } \\
\text { Depth } \\
\text { (m) }\end{array}$ & $\begin{array}{l}\text { Max. } \\
\text { Inflow } \\
(\mathrm{L} / \mathrm{s})\end{array}$ & $\begin{array}{l}\text { Max. } \\
\text { Resident } \\
\text { Volume }\left(\mathrm{m}^{3}\right)\end{array}$ & $\begin{array}{l}\text { Total Lost } \\
\text { Volume } \\
\left(\mathrm{m}^{3}\right)\end{array}$ & $\begin{array}{l}\text { Max. Outflow } \\
\text { (L/s) }\end{array}$ & $\begin{array}{l}\text { Total Discharge } \\
\text { Volume }\left(\mathrm{m}^{3}\right)\end{array}$ & Status \\
\hline D1a & 121 & 4.3 & 40.7 & 37.6 & 0.25 & 20.8 & 230.7 & OK \\
\hline D1b & 119.7 & 1.7 & 19.1 & 1.13 & 0.0 & 19.1 & 109.1 & OK \\
\hline D2 & 121 & 4 & 40.6 & 27.13 & 0.18 & 26 & 230.5 & OK \\
\hline R1 (section i) & 118.8 & 4.31 & 39.8 & 336.7 & 0.0 & 0.0 & 0.0 & OK \\
\hline R1 (section ii) & 118.2 & 4.28 & 39.8 & 312.7 & 0.0 & 0.0 & 0.0 & OK \\
\hline R2 (section i) & 119.2 & 4.21 & 26.1 & 228.4 & 0.0 & 0.0 & 0.0 & OK \\
\hline R2 (section ii) & 119.1 & 4.2 & 26 & 204.4 & 0.0 & 0.0 & 0.0 & OK \\
\hline
\end{tabular}




\section{Conflicts of interest}

There are no conflicts to declare.

\section{Acknowledgements}

The authors appreciate the support provided by the School of Engineering of the University of Greenwich.

\section{References}

1. CIRIA (Construction Industry Research and Information Association), Improving surface water management in refugee camps, Susdrain, 2018. Available from: https://www.susdrain.org/news/articles/improving_surfa ce_water_management_refugee_camps.html (Accessed on: $06-08-2019$ ).

2. L. R. Rossmiller, Types of Best Management Practices. In: Stormwater Design for Sustainable Development, Mc Graw Hill Education, New York, 2014, pp. 37 - 52. ISBN 978-0-07181652-6.

3. AFPNA (AFP News Agency), After drought, Kenya's Dadaab refugee camps hit by floods, AFP News Agency, 2018. [Online] Available from: https://www.youtube.com/watch?v=_CZRtMxK-SY (Accessed on: $06-08-2019$ ).

4. Anon, Ration cut in Kenya's refugee camps with no end to drought in sight, Africa Times, 3 October 2017.

5. Huhne and Slingo, Climate: Observations, Projections and Impact-Kenya. Met Office, United Kingdom, 2016.

6. D. Butler and J. Davies, Urban Drainage, $3^{\text {rd }}$ edn, Spon Press, Abingdon, 2011. ISBN 0-203-84905-1.

7. A. Bastable and L. Russell, Gap analysis in Emergency Water, Sanitation and Hygiene Promotion, Humanitarian Innovation Fund (HIF), 2013.

8. K. Tota-Maharaj, WASH in Emergencies Problem Exploration Report - Surface Water Drainage, Humanitarian Innovation Fund (HIF), 2016.
9. D. Alford-Daniel, C. Allen, A. S. Arne, M. Angeloni, E. Antheunissens, J. Ashmore, G. Baroni, G. Bramucci, J. Cameira, S. Derkinderen, S. Erb, F. Etienne, G. Federici, M. Hodgkin, C. Hoffman, B. Kelly, N. Motus, S. Ringel, K. Roberson, K. Ryan, D. Stone, V. Vogel, K. Vyas, P. White, J. Zarins, Camp Management Toolkit, International Organization for Migration (IOM), Norwegian Refugee Council (NRC) and UN Refugee Agency (UNHCR), 2015.

10. Arup \& Partners Ltd, Surface Water Management in Refugee Camps, Humanitarian Innovation Fund (HIF), 2017.

11. T. Chaosakul, T. Koottatep and K. N. Irvine, Low Impact Development Modelling to Assess Localized Flood Reduction in Thailand, Journal of Water Management Modelling, 2013; R246-18. doi: 10.14796/JWMM.R246-18.

12. C. Li, T. D. Fletcher, H. P. Duncan and M. J. Burns, Can storm-water control measures restore altered urban flow regimes at catchment scales? Journal of Hydrology, 2017; 549, pp. 631-653.

13. Sanderson Associates, Detailed drainage design services, Sanderson Associates Consultancy Engineers Ltd, Sanderson House, Jubilee Way Grange Moor, Huddersfield WF4 4TD, United Kingdom, 2019.

14. UNHCR (United Nations High Commissioner for Refugees), Dadaab Refugee Complex, United Nations High Commissioner for Refugees, Kenya, 2019a. [Online] Available from: https://www.unhcr.org/ke/dadaabrefugee-complex (Accessed on: $17-03-2019$ ).

15. UNHCR (United Nations High Commissioner for Refugees), UNHCR Kenya Dadaab Refugee Camp Update, United Nations High Commissioner for Refugees, Kenya, 2019b. [Online] Available from: https://igad.int/attachments/article/1513/FactSheet_Ken ya.pdf (Accessed on: 06-08-2019). 
16. T. Salmio, Refugees and the environment: an analysis and evaluation of the UNHCR's policies in $1992-2002$, Institute of Migration, 2009.

17. Kenya Meteorological Department, Agrometeorological Bulletins of Rainfall and Temperature Records for Garissa Station, Agro Meteorological Advisory Services Division, Kenya Meteorological Department, Dagoretti Corner, Ngong Road, Kenya, 2018.

18. World Weather and Climate, Average Monthly Weather in Garissa, Kenya, 2017. [Online] Available from: https://weather-and-climate.com/average-monthlyRainfall-Temperature-Sunshine,Garissa,Kenya (Accessed on: $31-07-2019)$.

19. Google Maps, Location of Dadaab refugee camp in Kenya, Eastern Africa, Google Maps, 2017.

20. A. B. Cambrézy, Refugee Camps and Environment: Landscape and Deforestation in Dadaab Region (Kenya), UNHCR - IRD, Dadaab, Kenya, 1999.

21. GoK (Government of Kenya), Sustainable Development in Kenya: Stocktaking in the run up to Rio+20, United Nations Conference on Sustainable Development, 2012.

22. B. Rono, Heavy Floods Hit Dadaab Refugee Camp, United Nations High Commissioner for Refugees (UNHCR), 2017.

23. M. J. Marriott, C. Nalluri and R. E. Featherstone, Civil Engineering Hydraulics: Essential Theory with Worked Examples, $5^{\text {th }}$ edn. rev. M. Marriott, Wiley-Blackwell, West Sussex, United Kingdom, 2009.

24. M. B. Abbott and A. W. Minns, Computational Hydraulics, $2^{\text {nd }}$ edn., Routledge, New York, 2016.
25. A. Chadwick, J. Morfett and M. Borthwick, Hydraulics in Civil and Environmental Engineering, 5th edn., CRC Press, London, 2013. ISBN 9780203813584.

26. W. James, L. A. Rossman and W. R. C. James, User's guide to SWMM 5, CHI, Guelph, Ontario, Canada, 2010. ISBN 9780-9808853-5-4.

27. L. A. Rossman and W. C. Huber, Storm-water Management Model Reference Manual - Hydrology (Revised) Volume 1, EPA/600/R-15/162A, United States Environmental Protection Agency (US EPA), Cincinnati, Ohio, USA, 2016.

28. R. Garcia, Hydraulic design manual, Directorate of the Design Division, Texas Department of Transportation, Texas, 2016.

29. R. Bhattacharya, Bermuda Grass, Bermuda attractions, 2019. [Online] Available from: https://www.bermudaattractions.com/bermuda_0000ee.htm (Accessed on: 05 $08-2019)$.

30. O. O. Ajibade and K. Tota-Maharaj, Comparative study of Sustainable Drainage Systems for stormwater management in refugee camps, Proceedings of the Institution of Civil Engineers - Municipal Engineer, ICE Publishing, UK, 2018; 171(3) pp. 149-162. ISSN 0965-0903 | E-ISSN 1751-7699.

31. UNHCR (United Nations High Commissioner for Refugees), WASH in camps, UNHCR Emergency Handbook, $4^{\text {th }}$ edn., United Nations High Commissioner for Refugees, Kenya, 2015.

32. D. Lantagne, C. Pezzi and A. Mahamud, Water Safety Plan: Dadaab Refugee Camps, Centres for Disease Control and Prevention, 2009. 